\title{
Dietary phosphorus restriction to half the minimum required amount slightly reduces weight gain and length of tibia, but sustains femur mineralization and prevents nephrocalcinosis in female kittens
}

\author{
BY F. J. H. PASTOOR', R. OPITZ', A. TH. VAN 'T KLOOSTER' AND \\ A. C. BEYNEN ${ }^{1,2}$ \\ ${ }^{1}$ Department of Laboratory Animal Science and ${ }^{2}$ Department of Large Animal Medicine and \\ Nutrition, Faculty of Veterinary Medicine, Utrecht University, Utrecht, The Netherlands
}

(Received 11 March 1994 - Revised 21 November 1994 - Accepted 6 December 1994)

\begin{abstract}
The effects of dietary $P$ restriction to half the recommended minimum level on growth, bone and renal mineralization and urinary composition were studied in female kittens. In two separate experiments, 8week-old weanling kittens were fed on purified diets containing either 4.6 or $9.2 \mathrm{mmol}$ P/MJ (2.8 or $5.6 \mathrm{~g}$ $\mathrm{P} / \mathrm{kg}$ diet). In the second experiment there was an additional low-P diet in which the $\mathrm{Ca}$ concentration was reduced from 9.5 to $4.8 \mathrm{mmol} / \mathrm{MJ}(7.5 \mathrm{v} .3 .8 \mathrm{~g} \mathrm{Ca} / \mathrm{kg}$ diet). $P$ restriction slightly but systematically reduced weight gain (to a maximum of $16 \%$ ) and growth of the tibia (by 1-4\%); the former effect was statistically significant $(P<0.05)$ between the ages of 15 and 20 weeks in Expt 1 only, and the latter did not reach statistical significance at any time point $(P \geqslant 0 \cdot 13)$. No adverse effect of $P$ restriction was found on mineralization of femur at the age of 39 weeks. Kidney Ca concentrations were significantly lowered (Expt 1, 6 v. $20 \mu \mathrm{mol} / \mathrm{g}$ dry weight, $P<0.001$; Expt 2,7 v. $16 \mu \mathrm{mol} / \mathrm{g}$ dry weight, $P<0.01$ ) in cats fed on the low-P diets, this effect not being affected by the dietary $C a: P$ ratio. Urinary $P$ concentration was significantly depressed (by $50-96 \%$ ) after feeding the low-P diets $(P<0.001)$. $P$ intake did not influence $\mathrm{P}, \mathrm{Ca}$ and $\mathrm{Mg}$ retention during the period of 15 to 39 weeks of age.
\end{abstract}

Phosphorus: Mineral excretion: Bone: Nephrocalcinosis: Cat

The minimum $P$ requirement of growing kittens has been set at $9 \cdot 2 \mathrm{mmol} P / \mathrm{MJ}$ dietary metabolizable energy (5.6 g P/kg diet; $19.7 \mathrm{MJ} / \mathrm{kg}$ diet; National Research Council, 1986). This recommendation is based on a single communication that kittens thrived on daily $\mathbf{P}$ intakes of 150 to $200 \mathrm{mg}$ (Scott, 1965). So far there are no additional reports to support or refute the current recommended $P$ intake of young cats.

$P$ restriction relative to the $P$ levels in most commercial cat diets could contribute to improved health of the cat (Finco, 1983). Diets with low levels of $P$ reduce nephrocalcinosis in cats (Lewis et al. 1978; Ross et al. 1982), which in turn counters the development and/or progression of renal insufficiency in these animals (Lewis et al. 1987). Renal failure is a major cause of death in cats (Cowgill, 1983). Urethral obstruction due to uroliths composed of struvite (magnesium ammonium phosphate hexahydrate) is also a common problem in cats (Lawler et al. 1985). Phosphate is a component of struvite, and low $P$ intakes reduce urinary phosphate concentrations (Pastoor et al. 1991 b), which may lower the risk of urolithiasis (Buffington et al. 1989). On the other hand, too extreme dietary $P$ restriction may impair bone mineralization in kittens as has been shown in young rats (Schoenmakers et al. 1989).

We have studied the effect of reduction of the dietary $\mathrm{P}$ level to half the minimum requirement (National Research Council, 1986) on growth, bone and renal mineralization, 
and urinary composition in female kittens. In the first experiment dietary $\mathbf{P}$ concentration was lowered while $\mathrm{Ca}$ remained at a constant level. The second experiment served to check the reproducibility of the first one and also to determine whether maintenance of a constant $\mathrm{Ca}: \mathbf{P}$ ratio affects the impact of dietary $\mathbf{P}$ restriction.

\section{MATERIALS AND METHODS}

The protocols of both experiments were approved by the animal experiments committee of the Department of Laboratory Animal Science, Utrecht University.

\section{Animals}

Female, 8-week-old weanling cats (Hsd/Cpb:CaDs; Harlan Cpb, Zeist, The Netherlands) were used throughout.

\section{Expt 1. Housing and diets}

The kittens were divided into two groups of ten animals each, which were stratified for body weight and litter. The groups were each housed in a separate stall $(2.1 \times 2.0 \times 3.0 \mathrm{~m})$ provided with resting shelves and a scratching post. The stalls were located in the same room. At 1-2 d before and during the balance periods (see below) the cats were housed individually in stainless steel cages $(1.16 \times 0.56 \times 0.67 \mathrm{~m})$ all placed in one room $(2.9 \times 5.9 \times 3.0 \mathrm{~m})$. In the two rooms a controlled light cycle (light: 07.00-19.00 hours), temperature $\left(20-23^{\circ}\right)$ and humidity $(50-65 \%)$ were maintained.

Within $3 \mathrm{~d}$ after arrival the cats were trained to eat a pelleted, purified diet, containing either 9.2 (normal) or 4.6 (low) $\mathrm{mmol} \mathrm{P} / \mathrm{MJ}(5.6 v .2 .8 \mathrm{~g} \mathrm{P} / \mathrm{kg}$ diet; Table 1). Except for the concentration of $P$ in the low-P diet, the two diets were formulated according to the minimum nutrient requirements of cats (National Research Council, 1986). $P$ was added in the form of $\mathrm{NaH}_{2} \mathrm{PO}_{4} \cdot 2 \mathrm{H}_{2} \mathrm{O}$ and the diets were balanced for $\mathrm{Na}$ using $\mathrm{Na}_{2} \mathrm{CO}_{3}$. The ingredients and analysed composition of the diets are given in Table 1 . The cats were given free access to the diets and demineralized water. Body weights of the cats were measured weekly.

\section{Expt 1. Interventions in the course of the experiment}

After 11 weeks (age 19 weeks) most cats in both dietary groups began to develop signs characteristic of biotin deficiency (Carey \& Morris, 1977). At week 15, for each dietary group half of the animals were supplemented orally with $0.5 \mathrm{mg}$ biotin/d. After another 2 weeks clinical signs in the supplemented cats had become less severe (Pastoor et al. 1991 b). We suggest that the pasteurized egg-white powder used as protein source (Table 1) still contained avidin, which rendered biotin unavailable. From week 17 (age 24 weeks) dietary levels of biotin were raised to $3 \mathrm{mg} / \mathrm{kg}$ (Table 1). After another 15 weeks (age 39 weeks) the clinical signs had disappeared and the condition of the cats, which was blindly evaluated by a veterinarian, was found to be similar for the low- and normal-P groups.

The temporary biotin deficiency might not have interfered with comparing the effects of the low- and normal-P diets. During the entire experiment the two groups as separate entities differed in $\mathrm{P}$ intake only. There were no signs of lagged growth. Body weights of our cats did not differ from those of their counterparts kept by the breeder and fed on a commercial diet. The oral biotin supplementation raised serum biotin levels measured after $16 \mathrm{~d}$ (Pastoor et al. 1991 a), but left unchanged plasma concentrations of $\mathrm{Ca}, \mathrm{Mg}, \mathrm{P}$, urea and creatinine and activity of alkaline phosphatase (EC 3.1.3.1) (results not shown).

\section{Expt 1. Collection of samples}

At the ages of $11,15,21,31$ and 39 weeks balance studies were performed. During periods of $6 \mathrm{~d}$ each the cats were housed individually. Twice daily they were allowed to leave their cages for $1 \mathrm{~h}$. Feed intake was recorded and $24 \mathrm{~h}$ samples of urine and faeces were collected 
Table 1. Composition of the experimental diets $* \dagger$

\begin{tabular}{|c|c|c|c|c|c|}
\hline & \multicolumn{2}{|c|}{ Expt 1} & \multicolumn{3}{|c|}{ Expt 2} \\
\hline & $\begin{array}{c}\text { Normal P } \\
\text { Normal Ca }\end{array}$ & $\begin{array}{c}\text { Low P } \\
\text { Normal Ca }\end{array}$ & $\begin{array}{c}\text { Normal P } \\
\text { Normal Ca }\end{array}$ & $\begin{array}{c}\text { Low } \mathbf{P} \\
\text { Normal } \mathrm{Ca}\end{array}$ & $\begin{array}{l}\text { Low P } \\
\text { Low Ca }\end{array}$ \\
\hline \multicolumn{6}{|l|}{ Ingredient (g/kg) } \\
\hline $\mathrm{NaH}_{2} \mathrm{PO}_{4} \cdot 2 \mathrm{H}_{2} \mathrm{O}$ & $21 \cdot 700$ & $7 \cdot 500$ & 21.790 & 7.719 & 7.719 \\
\hline $\mathrm{Na}_{2} \mathrm{CO}_{3}$ & $19 \cdot 280$ & 24.080 & 19.233 & 23.998 & 23.998 \\
\hline $\mathrm{CaCO}_{3}$ & 15.200 & 15.200 & $16 \cdot 118$ & $16 \cdot 118$ & 6.718 \\
\hline Dextrin & $339 \cdot 040$ & $348 \cdot 440$ & 337.899 & 347.205 & 356.605 \\
\hline Constant components $\ddagger$ & 604.780 & $604 \cdot 780$ & $604 \cdot 960$ & 604.960 & $604 \cdot 960$ \\
\hline \multicolumn{6}{|c|}{ Chemical analysis $(\mathrm{mmol} / \mathrm{kg}) \S$} \\
\hline $\mathbf{P}$ & 174 & 92 & 174 & 90 & 90 \\
\hline $\mathrm{Ca}$ & 179 & 177 & 182 & 182 & 90 \\
\hline $\mathrm{Mg}$ & 15 & 15 & 14 & 14 & 14 \\
\hline
\end{tabular}

* The metabolizable energy density of the diets was calculated to be $19 \cdot 7 \mathrm{MJ} / \mathrm{kg}$, using values of $16 \cdot 8,16.8$ and $37.8 \mathrm{~kJ} / \mathrm{g}$ for metabolizable energy contents of protein, carbohydrate and fat respectively.

$\dagger$ Calculated dietary P and Ca concentrations: Normal P 9.2 mmol P/MJ (5.6 g P/kg diet); Low P $4.6 \mathrm{mmol}$ $\mathrm{P} / \mathrm{MJ}$ (2.8 g P/kg diet); Normal Ca $9.5 \mathrm{mmol} \mathrm{Ca} / \mathrm{MJ}(7.5 \mathrm{~g} \mathrm{Ca} / \mathrm{kg}$ diet); Low Ca $4.8 \mathrm{mmol} \mathrm{Ca} / \mathrm{MJ}(3.8 \mathrm{~g} \mathrm{Ca} / \mathrm{kg}$ diet).

$\ddagger$ The constant components consisted of the following (g): egg-white $186 \cdot 5$, herring meal $56 \cdot 2$, beef tallow $197 \cdot 2$, maize oil 8.5, glucose 56.2, cooked maize starch 56.2, cellulose 11.2, $\mathrm{MgCO}_{3} 0.40$ (Expt 1) or 0.58 (Expt 2), taurine $0-38$, vitamin premix 12 , mineral premix 20 . The diets were formulated taking into account analysed $\mathrm{P}, \mathrm{Ca}$ and $\mathrm{Mg}$ concentrations in the egg-white and herring-meal preparations. These concentrations in Expts 1 and 2 were as follows (mmol/ $\mathrm{kg}$ product): egg-white; $\mathrm{P} 32.29$ and $24 \cdot 22, \mathrm{Ca} 9.98$ and 14.97, $\mathrm{Mg} 32.91$ and 24.68; herring meal; $\mathrm{P} 645 \cdot 79$ and 645.79, $\mathrm{Ca} 626.25$ and $426 \cdot 65, \mathrm{Mg} 81 \cdot 45$ and 74.04 . The vitamin premix consisted of $(\mathrm{mg} / 12 \mathrm{~g})$ : retinyl acetate and retinyl palmitate $(150 \mu \mathrm{g} / \mathrm{mg}) 6.3$, cholecalciferol $(12.5 \mu \mathrm{g} / \mathrm{mg}) 0.94$, DL- $\alpha$-tocopheryl acetate $(0.5$ $\mathrm{mg} / \mathrm{mg}$ ) $56 \cdot 6$, menadione $0 \cdot 094$, thiamin $4 \cdot 7$, riboflavin $3 \cdot 78$, pyridoxine $3 \cdot 78$, nicotinamide $37 \cdot 8$, DL-calcium pantothenic acid $(0.45 \mathrm{mg} / \mathrm{mg}) 10.48$, pteroylmonoglutamic acid 0.755 , cyanocobalamin $(1 \mu \mathrm{g} / \mathrm{mg}) 18.9$, choline chloride $(0.5 \mathrm{mg} / \mathrm{mg}$ ) 5228.46 , myoinositol 200, biotin 0.066 (Expt 1, up until week 16) or 3.0 (Expt 1, as from week 17 and Expt 2) and cooked maize starch 6427.345 or 6424.411 . The mineral premix consisted of $(\mathrm{mg} / 20 \mathrm{~g})$ : $\mathrm{KCl} 7191, \mathrm{FeSO}_{4} .7 \mathrm{H}_{2} \mathrm{O} 375 \cdot 6, \mathrm{CuSO}_{4} .5 \mathrm{H}_{2} \mathrm{O} 18 \cdot 5, \mathrm{MnO}_{2} 7 \cdot 4, \mathrm{ZnCl}_{2} 98 \cdot 3, \mathrm{KI} 0 \cdot 45, \mathrm{Na}_{2} \mathrm{SeO}_{3} .5 \mathrm{H}_{2} \mathrm{O} 0 \cdot 31$, cooked maize starch $12308 \cdot 44$.

$\S$ Results are mean values for the analysis of four batches of food within each experiment.

each day. The method used to collect excreta has been published previously (Pastoor et al. 1990).

At $7 \mathrm{~d}$ after the start of the experiment and at the end of each balance period the cats were anaesthetized ( $0.2 \mathrm{mg}$ atropine and $20 \mathrm{mg}$ ketamine $/ \mathrm{kg}$ administered intramuscularly, and $0.5 \mathrm{mg}$ xylazine $/ \mathrm{kg}$ administered subcutaneously). Blood was taken from the jugular vein and samples were collected in heparinized tubes. An X-ray photograph (MCD 125; Philips, Eindhoven, The Netherlands) of the tibia of each cat was made. A leaden ruler was photographed simultaneously to determine bone length on the X-ray photographs.

Immediately after blood sampling at the age of 39 weeks the anaesthetized cats were killed by an overdose of sodium pentobarbital (0.4-0.8 g/animal administered intravenously). Kidneys, heart, liver and left femur and tibia were removed. Kidney capsules were discarded. The organs were weighed and frozen at $-20^{\circ}$ until chemical analysis, except for the right kidney which was fixed in $100 \mathrm{ml} / 1$ neutral phosphate-buffered formalin for histological examination.

\section{Expt 2. Housing and diets}

Three groups of eight kittens each, which were stratified for body weight and litter, were housed in separate stalls $(2.2 \times 2.6 \times 3.0 \mathrm{~m})$ in the same room $(8 \times 6 \times 3 \mathrm{~m})$. Each stall had four open stainless steel cages $(1.16 \times 0.56 \times 0.67 \mathrm{~m})$. During the balance period (see below) 


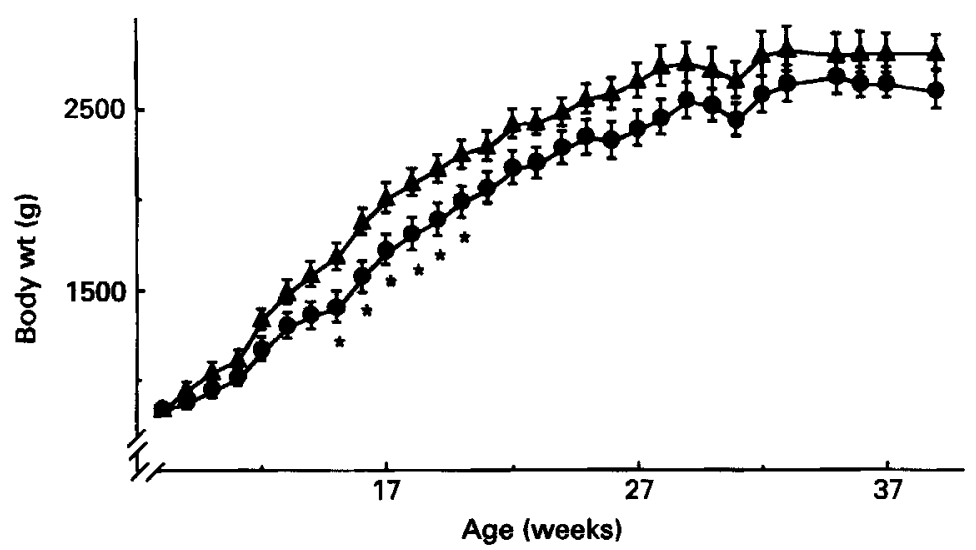

Fig. 1. Expt 1. Time course of body-weight gain of female cats fed on diets containing either 4.6 or $9.2 \mathrm{mmol}$ phosphorus/MJ. Values are means for ten cats, with their standard errors indicated by vertical bars. (A), Normalphosphorus diet; (O), low-phosphorus diet. Student's $t$ test was performed to compare the two dietary groups at the same age: ${ }^{*} P<0.05$.

four extra cages were placed in each stall. For the last 5 weeks of the experiment the cats were kept in another room $(8 \times 6 \times 3 \mathrm{~m})$ in which each group again had its own stall $(1.6 \times 2.6 \times 3.0 \mathrm{~m})$. In the rooms, lighting (light: $07.00-19.00$ hours), temperature $\left(18-23^{\circ}\right)$ and humidity (50-70\%) were controlled.

Within $3 \mathrm{~d}$ after arrival the cats ate one of the three purified, experimental diets (Table 1). Two diets were almost identical to those used in Expt 1; they contained either 4.6 (low) or 9.2 (normal) mmol P/MJ (2.8 v. $5.6 \mathrm{~g} \mathrm{P} / \mathrm{kg} \mathrm{diet)}$ and the minimum required (National Research Council, 1986) Ca level of 9.5 (normal) mmol/MJ (7.5 g Ca/kg diet). In the third diet both $\mathrm{P}$ and $\mathrm{Ca}$ levels were reduced ( $4.6 \mathrm{mmol} \mathrm{P}$ and $4.8 \mathrm{mmol} \mathrm{Ca} / \mathrm{MJ} ; 2.8 \mathrm{~g} \mathrm{P}$ and $3.8 \mathrm{~g}$ $\mathrm{Ca} / \mathrm{kg}$ diet) so that the $\mathrm{Ca}: \mathrm{P}$ ratio was the same as that in the normal-P, normal-Ca diet. The ingredients and analysed composition of the diets are given in Table 1 . The cats were given free access to the diets and demineralized water. Body weights of the cats were recorded weekly.

\section{Expt 2. Interventions in the course of the experiment}

From the start of the experiment the cats did not grow well. After 3 weeks they were found to have coccidiosis. They were then treated for $9 \mathrm{~d}$ with sulphamethoxypyridazin (50 $\mathrm{mg} / \mathrm{kg}$ on days 1 and $7 ; 25 \mathrm{mg} / \mathrm{kg}$ on days 2, 3,8 and 9). After this treatment the kittens were free from coccidiosis. From 2 to 6 weeks after the start of the experiment, six cats (one fed on the low-P, normal-Ca diet; five fed on the low-P, low-Ca diet) were found to be in shock. The cats showed hypersalivation, a fall in body temperature and finally lost consciousness. They were each given saline $(9 \mathrm{~g} \mathrm{NaCl} / 1 ; 10 \mathrm{ml} / \mathrm{animal}$, subcutaneously), prednisolone $(0.4 \mathrm{mg} /$ animal, intramuscularly) and 1-cyclopropyl-7-(4-ethyl-1-piperazinyl)-6-fluor-1,4-dihydro-4-oxo-3-chinoline carbonate ( $5 \mathrm{mg} /$ animal, subcutaneously) after which they recovered within a few hours, except for a cat of the low-P, low-Ca group, which died. Affected cats were clinically evaluated, but no abnormalities could be detected. Autopsy of the dead cat did not give any clues to the cause of the shock. After week 5 of the experiment all cats grew well and by week 8 (age 15 weeks) group means of body weights had reached normal values, i.e. body-weight values for kittens of the same age but fed on a commercial diet, as based on data provided by the breeder. One cat which was fed on the normal-P, normal-Ca diet had to be removed from the experiment in week 8 , because it did not thrive on the purified diet. After transfer to a commercial cat diet this animal rapidly attained a good condition. 


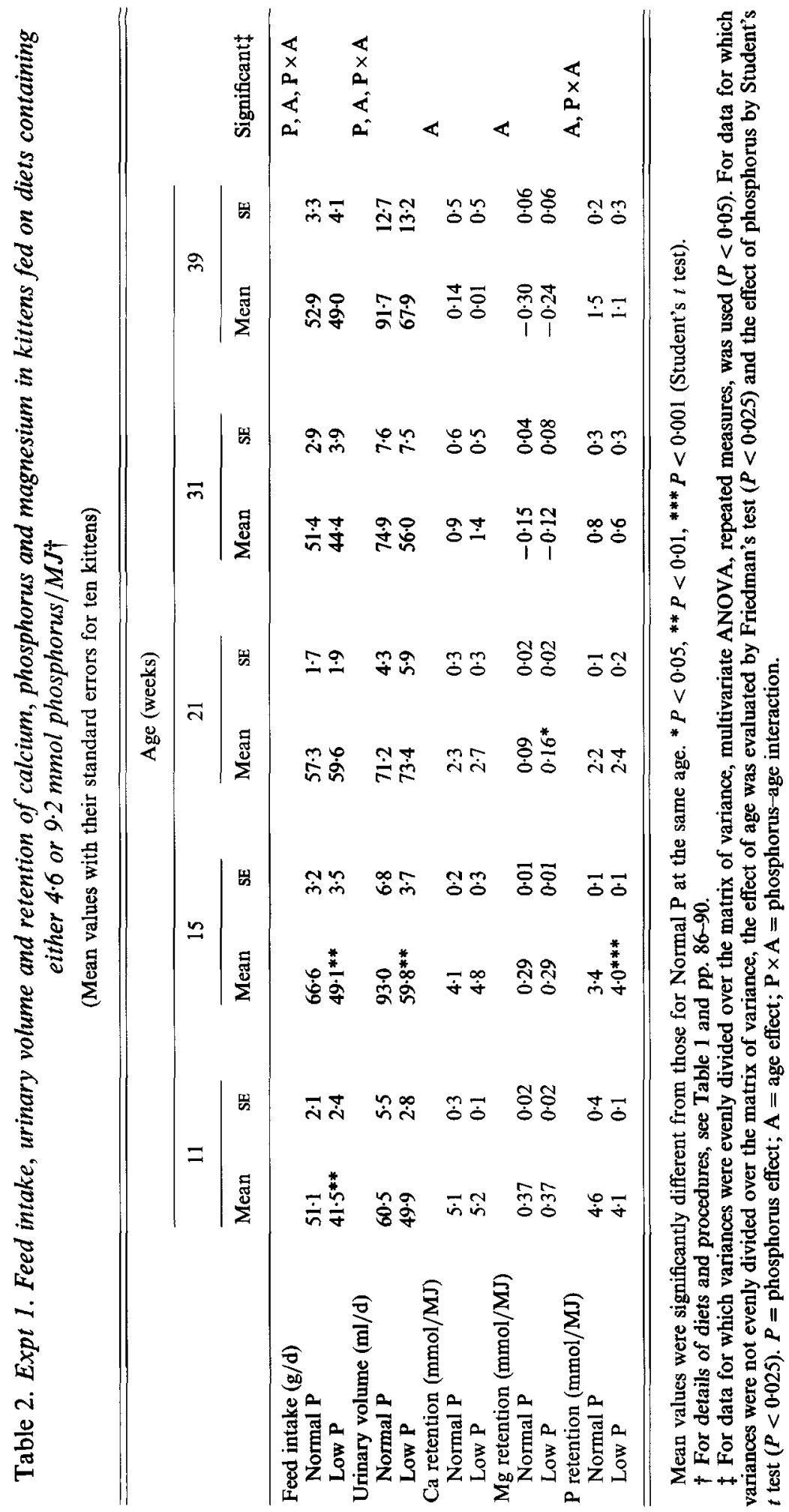




\section{Expt 2. Collection of samples}

Blood samples and X-ray photographs were taken at the ages of 9,23,31 and 39 weeks. A balance study was performed when the cats were 31 weeks old. At the end of the study the cats, aged 39 weeks, were killed and organs and bones were removed as described above.

\section{Preparation of samples}

Samples of faeces, urine, plasma, organs and bones were prepared for analysis as described previously (Pastoor et al. 1994a, b).

For histological examination, 5- $\mu \mathrm{m}$-thick longitudinal sections of each kidney were stained with Von Kossa's solution for detection of phosphate-containing deposits (Mallory, 1961). The severity of nephrocalcinosis was scored blind and in random order on a scale from 0 (no deposits) to 3.

\section{Chemical analyses}

$\mathrm{Ca}, \mathrm{Mg}$ and $\mathrm{P}$ in feed, faeces, urine, plasma, organs and femurs, plasma activity of alkaline phosphatase, and levels of creatinine and urea in plasma and urine were analysed as described previously (Pastoor et al. 1994a). Hydroxyproline in non-acidified urine was determined using a Hypronosticon test-combination kit (Organon Teknika Ltd, Boxtel, The Netherlands). Urinary $\mathrm{pH}$ was measured with an electrode ( $\mathrm{Phm} 83$ autocal $\mathrm{pH}$ meter; Radiometer, Copenhagen, Denmark). We had found earlier that the $\mathrm{pH}$ of freshly voided urine increased while in the litter box during the day, and thus we corrected the $\mathrm{pH}$ of the $24 \mathrm{~h}$ samples using a regression line, $Y=2.222+0.647 X(r 0.87, P<0.001, n 18)$, established with urine samples of which the $\mathrm{pH}$ was measured immediately after micturition $(Y)$ and 16-24 h later $(X)$. The range of the $X$ values was 8.0-9.6, which corresponded with that for the urinary $\mathrm{pH}$ values measured in the present studies.

For all chemical analyses accuracy was verified to be within $5 \%$ deviation from the targets with the use of reference samples (reference serum, Roche N; Roche Diagnostica, Basel, Switzerland and in-house reference pools of feed, faeces and urine).

\section{Statistical analyses}

All statistical analyses were carried out according to Steel \& Torrie (1981) and using a SPSS/PC + computer program (SPSS Inc., 1988 $a, b$ ). The two-sided level of statistical significance was pre-set at $P<0.05$. Multivariate analysis of variance (MANOVA), repeated measures, was used to evaluate effects of age, diet and their interaction. When in Expt 1 the variances were not evenly divided over the matrix of variance, even after logarithmic transformation of the data, the effect of age was evaluated by Friedman's test $(P<0.025)$ and the effect of diet by Student's $t$ test $(P<0.025)$. Group means for the same age were compared by Student's $t$ test or, when data were not normally distributed, by the Mann-Whitney U test. Group means in Expt 2 were compared by one-way ANOVA followed by the Tukey test or, for non-normally distributed data, by the Kruskal-Wallis test followed by Mann-Whitney $U$ tests. To take into account the greater probability of a type 1 error due to multiple comparisons, the level of statistical significance was reduced to $P<0.017$ (Bonferroni's adaptation).

\section{RESULTS}

The numerical values of data mentioned but not shown here can be found elsewhere (Pastoor, 1993).

\section{Expt 1. Body weight and feed intake}

Fig. 1 shows that mean body weights of kittens fed on the low-P diet were systematically lower than those of cats fed on the normal-P diet; between the ages of 15 and 20 weeks the 
difference was statistically significant. During the balance periods at 11 and 15 weeks of age the cats fed on the low-P diet ate significantly less (Table 2).

\section{Expt 1. Mineral retention and absorption}

In order to facilitate direct comparisons of data from periods or diets with different feed intakes, mineral retention was expressed as $\mathrm{mmol} / \mathrm{MJ}$ metabolizable dietary energy (Table 2). Retention was calculated as intake minus urinary-plus-faecal excretion. Ca retention fell during the course of the experiment, and did not differ significantly from zero at the age of 31 to 39 weeks. The low-P diet did not influence retention of $\mathrm{Ca}$. Retention of $\mathrm{Mg}$ dropped with age and at the ages of 31-39 weeks group means were negative. The amount of $\mathbf{P}$ in the diet did not systematically affect $\mathrm{Mg}$ retention. MANOVA yielded significant effects of age and diet-age interaction on retention of P. Except for the first balance period during which feed intake and absolute retention of $\mathbf{P}(\mathrm{mmol} / \mathrm{d})$ were significantly depressed in the low-P group, absolute $\mathrm{P}$ retention was not influenced by dietary $\mathrm{P}$ level (results not shown).

Fig. 2 shows the time course of percentages of apparent absorption of $\mathrm{Ca}, \mathrm{Mg}$ and $\mathrm{P}$. Apparent absorption was calculated as intake minus faecal excretion and expressed as a percentage of intake. MANOVA revealed a significant lowering effect of age on absorption of $\mathrm{Ca}$ and $\mathrm{Mg}$. Absorption of $\mathrm{Ca}$ and $\mathrm{Mg}$ tended to be somewhat higher in the low-P group. The percentage apparent $\mathbf{P}$ absorption was affected by age and dietary $\mathbf{P}$ level; it was consistently lower in the low-P group and dropped with age.

\section{Expt 1. Urinary composition}

Urinary volume expressed as $\mathrm{ml} / \mathrm{d}$ was lower in the low-P group (Table 2), but when expressed as $\mathrm{ml} / \mathrm{g}$ feed it was similar for both dietary groups (results not shown). Urinary $\mathrm{pH}$ was slightly higher in the low-P group (Fig. 3). Low $\mathbf{P}$ intake was initially associated with a higher urinary concentration of $\mathrm{Ca}$, which disappeared when the cats grew older. Urinary concentrations of $\mathrm{Mg}$ were systematically higher in the low-P group. Urinary $\mathrm{P}$ levels were significantly depressed when $P$ intake was reduced. In the low-P group urinary concentration of $P$ rose with age up to 31 weeks.

\section{Expt 1. Plasma minerals}

Plasma $\mathrm{Ca}$ levels were not influenced by dietary $\mathbf{P}$ concentration, but dropped slightly with age (results not shown). MANOVA yielded a significant effect of age and diet-age interaction on plasma concentration of $\mathrm{Mg}$ : at the ages of 9 and 11 weeks plasma $\mathrm{Mg}$ concentrations were slightly lower in the low-P group, but at the ages of 15 and 31 weeks the opposite was seen (results not shown). Plasma levels of $P$ were significantly affected by dietary $P$ level, age and diet-age interaction. At the ages of 11 and 15 weeks, plasma levels of $P$ were significantly reduced in the low-P group (1.8 (SE 0.2$)$ and 2.2 (SE 0.1$) \mathrm{mmol} / 1 \mathrm{v}$. $2 \cdot 6$ (SE 0.1) and $2 \cdot 5$ (SE $0 \cdot 1) \mathrm{mmol} / 1, n$ 10). Plasma levels of $P$ dropped with ageing.

\section{Expt 1. Urea and creatinine levels}

Plasma levels of urea and creatinine were not affected by dietary P level (results not shown), but rose with age. Urinary excretion of urea and creatinine clearance dropped with age, and were not systematically influenced by $\mathrm{P}$ intake (results not shown).

\section{Expt 1. Bone development}

There was a strong correlation $(r 0.99, P<0.001, n 20)$ between the length of the tibia as estimated from X-ray photographs taken just before necropsy and that measured directly thereafter. During the course of the experiment tibias were systematically, but not 


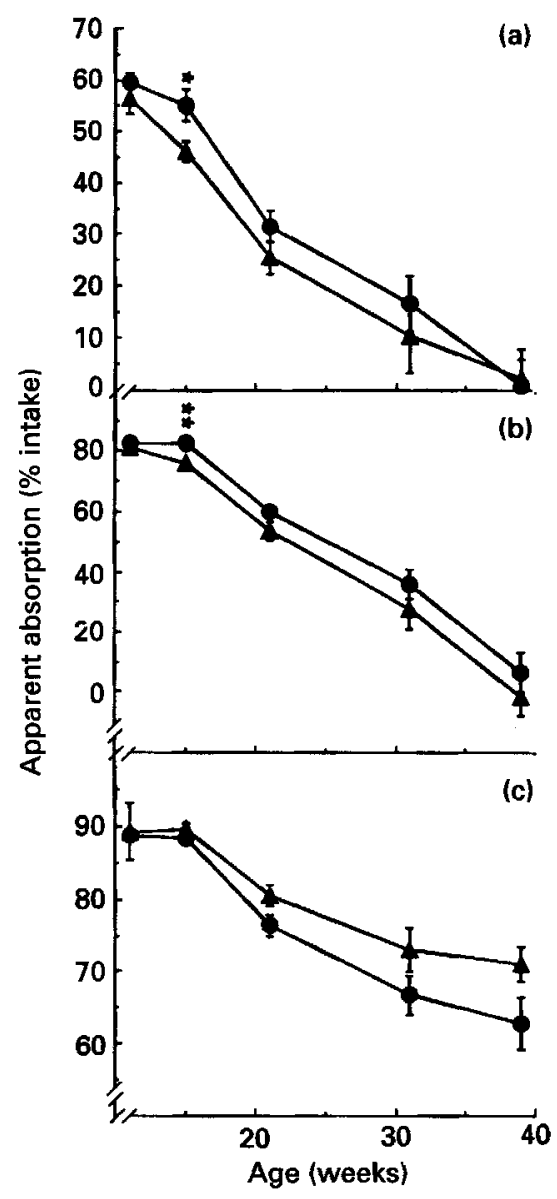

Fig. 2. Expt 1. Time course of change in percentage apparent absorption of (a) calcium, (b) magnesium and (c) phosphorus in female cats fed on diets containing either 4.6 or $9.2 \mathrm{mmol}$ phosphorus/MJ. Values are means for ten cats with their standard errors indicated by vertical bars. (A), Normal-phosphorus diet; ( $O$ ), low-phosphorus diet. Multivariate ANOVA, repeated measures $(P<0.05)$, revealed significant effects of age on the percentage apparent absorption of calcium, magnesium and phosphorus. The percentage apparent absorption of phosphorus was also affected by dietary phosphorus level. Student's $t$ test was performed to compare the two dietary groups at the same age: $* P<0.05, * * P<0.01$.

significantly, shorter in the cats fed on the low-P diet (Fig. 4). Plasma activity of alkaline phosphatase, which is an indicator of bone formation, and urinary excretion of hydroxyproline, which is an indicator of bone resorption, were not influenced by $P$ intake (results not shown) but dropped from 2.9 (SE 0.2) $\mu \mathrm{kat} / 1$ and 62 (SE 4) $\mathrm{mmol} / \mathrm{d} \mathrm{per} \mathrm{kg}$ body weight (BW) at the age of 15 weeks to 1.0 (SE 0.1) $\mu \mathrm{kat} / 1$ and 17 (SE 1) mmol/d per kg BW ( $n$ 20) at the age of 39 weeks.

Dietary P level did not significantly affect final (age 39 weeks) length, circumference, weight, volume and density of the femur (results not shown); average values were $9 \cdot 7$ (SE 0.1) cm, 2.6 (SE 0.03) cm, 6.4 (SE 0.2) g, 5.1 (SE 0.1) $\mathrm{cm}^{3}$ and $1.27(\mathrm{SE} 0.01) \mathrm{g} / \mathrm{cm}^{3}(n$ 20) respectively. Femur ash, expressed on a dry weight basis, was slightly, but significantly, elevated in cats fed on the low-P diet (642 (SE 4) v. 630 (SE 2) mg/g, $n 10, P<0.05$ ). Femur Ca content was significantly raised in the low-P group when expressed on a dry weight basis (233 (SE 1) v. 228 (SE 1) $\mathrm{mg} / \mathrm{g}, n 10, P<0.05$ ), but not when expressed as $\mathrm{mmol} / \mathrm{cm}^{3}$ (results 


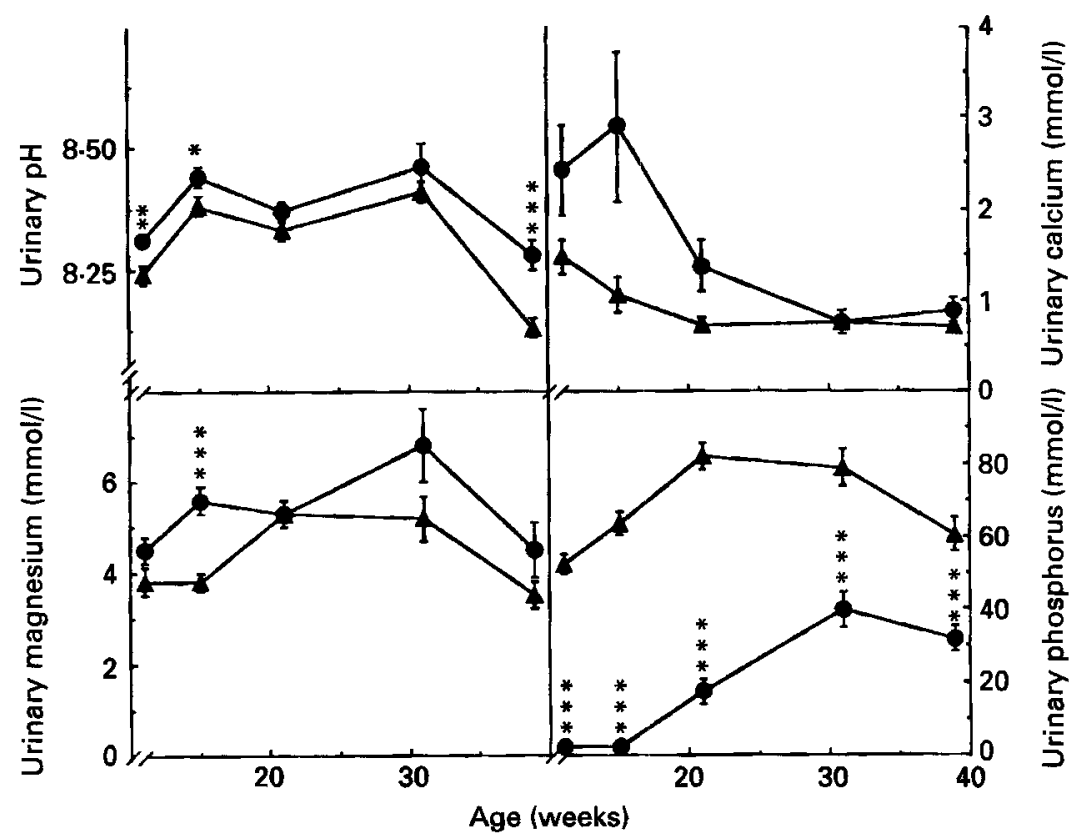

Fig. 3. Expt 1. Time course of changes in urinary $\mathrm{pH}$ and urinary concentrations of calcium, magnesium and phosphorus in female cats fed on diets containing either 4.6 or $9.2 \mathrm{mmol}$ phosphorus/MJ. Values are means for ten cats with their standard errors indicated by vertical bars. (A), Normal-phosphorus diet; (O), low-phosphorus diet. Multivariate ANOVA, repeated measures $(P<0.05)$, revealed significant effects of age and dietary phosphorus level on urinary $\mathrm{pH}$ and urinary concentrations of calcium, magnesium and phosphorus. Urinary concentrations of magnesium and phosphorus were also affected by diet-age interaction. Student's $t$ test was performed to compare the two dietary groups at the same age : ${ }^{*} P<0.05,{ }^{* *} P<0.01,{ }^{* * *} P<0.001$.

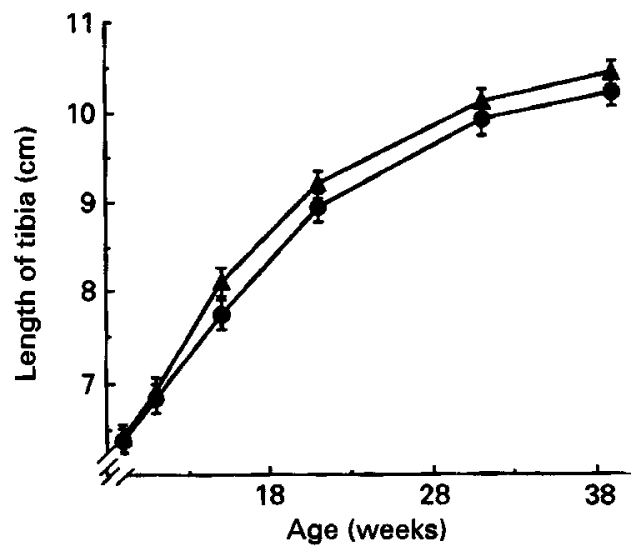

Fig. 4. Expt 1. Time course of growth of the tibia of female cats fed on diets containing either 4.6 or $9.2 \mathrm{mmol}$ phosphorus/MJ. Values are means for ten cats with their standard errors indicated by vertical bars. (A), Normalphosphorus diet; (O), low-phosphorus diet. Multivariate ANOVA, repeated measures $(P<0.05)$, revealed significant effects of age and diet-age interaction on the length of the tibia. Student's $t$ test was performed to compare the two dietary groups at the same age: $P=0 \cdot 13-0 \cdot 85$. 
Table 3. Expts 1 and 2. Mineral composition of kidneys in kittens fed on diets containing various amounts of phosphorus and calcium $\dagger$

(Mean values with their standard errors for ten kittens (Expt 1) or seven to eight kittens (Expt 2))

\begin{tabular}{|c|c|c|c|c|c|c|c|c|c|c|}
\hline & \multicolumn{4}{|c|}{ Expt 1} & \multicolumn{6}{|c|}{ Expt 2} \\
\hline & \multicolumn{2}{|c|}{$\begin{array}{c}\text { Normal P } \\
\text { Normal Ca }\end{array}$} & \multicolumn{2}{|c|}{$\begin{array}{c}\text { Low P } \\
\text { Normal Ca }\end{array}$} & \multicolumn{2}{|c|}{$\begin{array}{c}\text { Normal P } \\
\text { Normal Ca }\end{array}$} & \multicolumn{2}{|c|}{$\begin{array}{c}\text { Low P } \\
\text { Normal } \mathrm{Ca}\end{array}$} & \multicolumn{2}{|c|}{$\begin{array}{c}\text { Low P } \\
\text { Low Ca }\end{array}$} \\
\hline & Mean & SE & Mean & SE & Mean & $\mathbf{S E}$ & Mean & SE & Mean & SE \\
\hline \multicolumn{11}{|c|}{ Kidney mineral content $(\mu \mathrm{mol} / \mathrm{g}$ dry wt) } \\
\hline $\begin{array}{l}\mathrm{Ca} \\
\mathbf{M g} \\
\mathbf{P}\end{array}$ & $\begin{array}{r}20 \\
23 \\
320\end{array}$ & $\begin{array}{l}9 \\
0.9 \\
9\end{array}$ & $\underbrace{6^{* * *}}$ & $\begin{array}{l}0 \cdot 2 \\
0 \cdot 4 \\
6\end{array}$ & $\begin{array}{c}16^{\mathrm{a}} \\
25 \\
370\end{array}$ & $\begin{array}{l}5 \\
0 \cdot 4 \\
6\end{array}$ & $\begin{array}{r}7^{b} \\
25 \\
369\end{array}$ & $\begin{array}{l}0.2 \\
0.1 \\
6\end{array}$ & $\begin{array}{r}7^{b} \\
26 \\
366\end{array}$ & $\begin{array}{l}0 \cdot 2 \\
0 \cdot 6 \\
4\end{array}$ \\
\hline
\end{tabular}

a, b Mean values within Expt 2 not sharing a common superscript letter were significantly different, $P<0 \cdot 017$ (Mann-Whitney U test).

*** Mean value was significantly different from Normal $P$, Normal $\mathrm{Ca}, P<0.001$ (Mann-Whitney $U$ test).

$\dagger$ In Expt 2 the Krustal-Wallis test was performed to compare the three dietary groups: Kidney calcium content, $P<0.01$. For details of diets and procedures, see Table 1 and pp. 86-90.

‡ Calculated dietary $\mathrm{P}$ and $\mathrm{Ca}$ concentrations were: Normal $\mathrm{P} 9.2 \mathrm{mmol} \mathrm{P} / \mathrm{MJ}(5.6 \mathrm{~g} \mathrm{P} / \mathrm{kg}$ diet); Low $\mathrm{P}$ $4.6 \mathrm{mmol} \mathrm{P} / \mathrm{MJ}$ (2.8 g P/kg diet); Normal Ca $9.5 \mathrm{mmol} \mathrm{Ca} / \mathrm{MJ}$ (7.5 g Ca/kg diet); Low Ca $4.8 \mathrm{mmol} \mathrm{Ca} / \mathrm{MJ}$ (3.8 $\mathrm{g} \mathrm{Ca} / \mathrm{kg} \mathrm{diet})$.

not shown). Dietary $\mathrm{P}$ level did not influence femur $\mathrm{Mg}$ and $\mathrm{P}$ concentrations (results not shown); average values were 3.8 (SE 0.04) and 99 (SE 1) $\mathrm{mg} / \mathrm{g}$ dry weight ( $n$ 20).

\section{Expt 1. Mineral concentrations of organs}

$\mathrm{Ca}, \mathrm{Mg}$ and $\mathrm{P}$ concentrations of heart and liver were similar for both dietary groups (results not shown). Kidney $\mathrm{Ca}$ was significantly depressed in the low-P group, but concentrations of $\mathrm{Mg}$ and $\mathrm{P}$ were unchanged (Table 3). Histological examination of kidneys revealed calcified foci, which were mainly located in the corticomedullary junction and the inner stripe of the outer medulla. Deposits were probably located in the lumen of Henle's loop and/or collecting tubules, but due to the distortion of the cells the exact location could not be determined. Histological scores for nephrocalcinosis in the cats fed on the low-P diet were significantly $(P<0.001)$ lower than in those fed on the normal-P diet (medians were 0.25 and 1 respectively). Histological scores were strongly correlated with chemically analysed renal Ca contents (Spearman rank-order correlation coefficient $r 0.92, P<0.001$, $n$ 19) (Fig. 5).

\section{Expt 2. Body weight}

During the course of the experiment, body weights of the three dietary groups were not significantly different, but at 20 weeks of age cats fed on the low-P, low-Ca diet were systematically lighter than those fed on the other diets (Fig. 6). From 9 to 20 weeks of age the kittens given the low-P, normal-Ca diet had somewhat lower group mean body weights than those fed on the normal-P, normal-Ca diet.

\section{Expt 2. Mineral retention and absorption}

In the 31-week-old cats, feed intake of the three dietary groups was similar (Table 4). Ca, $\mathrm{Mg}$ and $\mathrm{P}$ retention were not affected by dietary composition. In all three dietary groups group mean retention of $\mathrm{Mg}$ was negative.

Percentages of apparent absorption of $\mathrm{Ca}$ and $\mathrm{Mg}$ were not significantly affected by 


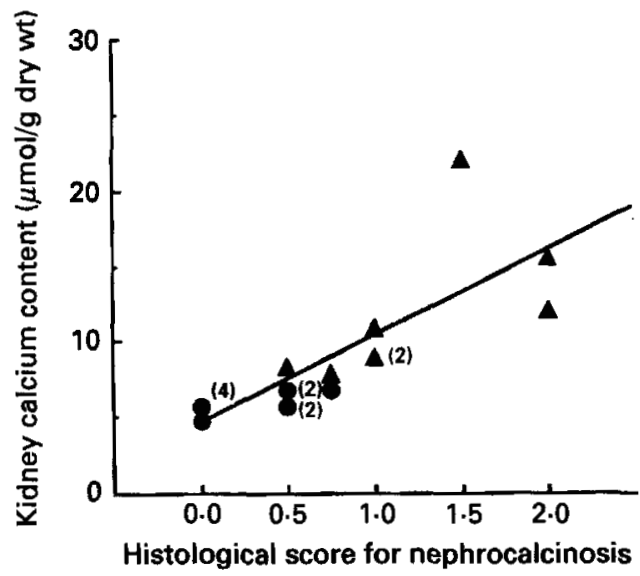

Fig. 5. Expt 1. Relation between histological scores for nephrocalcinosis and chemically analysed renal calcium contents in 39-week-old female cats fed on diets containing either 4.6 or 9.2 mmol phosphorus/MJ. (A), Normalphosphorus diet; (O), low-phosphorus diet. When two or more points coincide, the number is indicated. The Spearman rank-order correlation coefficient was $0.92(P<0.001, n 19)$ and including an outlier not shown (score, 2 ; kidney calcium, $97 \mu \mathrm{mol} / \mathrm{g}$ dry weight) it was $R 0.93(P<0.001, n 20)$. Although nephrocalcinosis score is a discrete variable, Pearson's line of regression is shown: $Y=4.67+5 \cdot 43 X(r 0.80, P<0 \cdot 001, n 19)$.

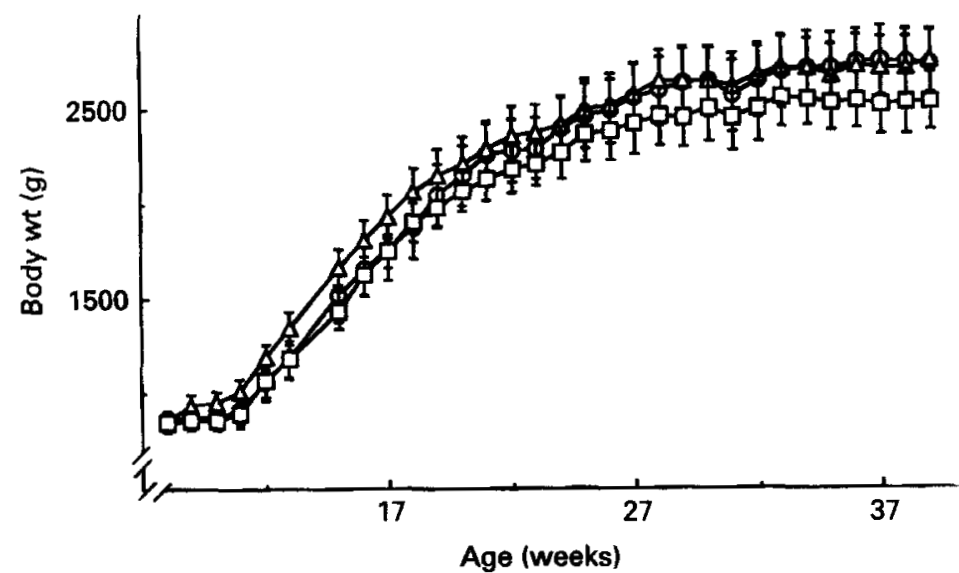

Fig. 6. Expt 2. Time course of body-weight gain of fernale cats fed on diets containing either $4.6 \mathrm{or} 9.2 \mathrm{mmol}$ phosphorus and 4.8 or $9.5 \mathrm{mmol}$ calcium/MJ. Values are means for seven or eight cats with their standard errors indicated by vertical bars. $(\triangle)$, Normal-phosphorus, normal-calcium diet; $(O)$, low-phosphorus, normal-calcium diet; $(\square)$, low-phosphorus, low-calcium diet. One-way ANOVA was performed to compare the three dietary groups at the same age: $P=0.54-0.99$.

dietary composition but group means were highest in cats fed on the low-P, low-Ca diet (Table 4). The percentage $P$ absorption in cats fed on the low-P, low-Ca diet was significantly higher than in cats fed on the low-P, normal-Ca diet. An intermediate value was seen in the cats fed on the normal-P, normal-Ca diet.

\section{Expt 2. Urinary composition}

Urinary volume, $\mathrm{pH}$ and urinary concentrations of $\mathrm{Ca}$ and $\mathrm{Mg}$ were not significantly affected by dietary composition (Table 4). Urinary concentrations of $P$ were significantly reduced in cats fed on the low-P diets. 
Table 4. Expt 2. Feed intake, urinary volume, $\mathrm{pH}$ and retention, absorption percentages and urinary concentrations of calcium, magnesium and phosphorus in 31-week-old, female cats fed on diets containing various amounts of calcium and phosphorus*

(Mean values with their standard errors for eight (Low P, Normal Ca) or seven (Normal P, Normal Ca; Low $\mathrm{P}$, Low $\mathrm{Ca}$ ) kittens)

\begin{tabular}{|c|c|c|c|c|c|c|}
\hline \multirow[t]{2}{*}{ Dietary treatment $\dagger \ldots$} & \multicolumn{2}{|c|}{ Normal P, Normal Ca } & \multicolumn{2}{|c|}{ Low $\mathbf{P}$, Normal Ca } & \multicolumn{2}{|c|}{ Low $\mathrm{P}$, Low Ca } \\
\hline & Mean & SE & Mean & SE & Mean & SE \\
\hline Feed intake $(g / d)$ & $36 \cdot 1$ & $2 \cdot 8$ & $35 \cdot 2$ & 3.9 & 35.8 & $4 \cdot 1$ \\
\hline Urinary volume $(\mathrm{ml} / \mathrm{d})$ & $52 \cdot 6$ & $4 \cdot 0$ & $55 \cdot 7$ & $5 \cdot 9$ & $54 \cdot 8$ & $7 \cdot 0$ \\
\hline Urinary $\mathrm{pH}$ & $8 \cdot 2$ & 0.04 & $8 \cdot 2$ & $0 \cdot 02$ & $8 \cdot 2$ & 0.05 \\
\hline \multicolumn{7}{|l|}{ Retention (mmol/MJ) } \\
\hline $\mathrm{Ca}$ & 0.9 & $0 \cdot 7$ & 0.5 & $0 \cdot 8$ & 0.9 & 0.3 \\
\hline $\mathrm{Mg}$ & -0.16 & $0 \cdot 06$ & -0.22 & 0.06 & -0.17 & 0.07 \\
\hline $\mathbf{P}$ & 0.6 & 0.4 & 0.1 & $0 \cdot 4$ & 0.7 & 0.3 \\
\hline \multicolumn{7}{|l|}{ Absorption ( $\%$ intake) } \\
\hline $\mathrm{Ca}$ & $10 \cdot 5$ & $7 \cdot 3$ & $5 \cdot 8$ & $7 \cdot 3$ & $21 \cdot 7$ & $6 \cdot 2$ \\
\hline $\mathbf{M g}$ & $25 \cdot 8$ & $7 \cdot 4$ & 25.4 & $5 \cdot 6$ & 40.8 & 67 \\
\hline $\mathrm{P}$ & $65 \cdot 2^{a, b}$ & $2 \cdot 4$ & $53 \cdot 2^{\mathrm{b}}$ & $5 \cdot 1$ & $76 \cdot 8^{a}$ & $4 \cdot 0$ \\
\hline \multicolumn{7}{|c|}{$\begin{array}{l}\text { Urinary mineral concentration } \\
(\mathrm{mmol} / \mathrm{l})\end{array}$} \\
\hline $\mathrm{Ca}$ & 0.75 & 0.08 & 0.93 & $0 \cdot 10$ & 1.01 & 0.14 \\
\hline $\mathrm{Mg}$ & $4 \cdot 7$ & $0 \cdot 3$ & $5 \cdot 0$ & $0 \cdot 3$ & 6.0 & 0.6 \\
\hline $\mathbf{P}$ & $69 \cdot 0^{\mathrm{a}}$ & $3 \cdot 9$ & $28 \cdot 1^{b}$ & $3 \cdot 4$ & $37 \cdot 1^{\mathrm{b}}$ & $3 \cdot 2$ \\
\hline
\end{tabular}

a, b Mean values within a row not sharing a common superscript letter were significantly different, $P<0 \cdot 05$ (Tukey's test).

* One-way ANOVA was performed to compare the three dietary groups: $\mathrm{P}$ absorption, $P<0.01$; urinary $\mathrm{P}$ concentration, $P<0.001$. For details of diets and procedures, see Table 1 and pp. 86-90.

$\uparrow$ Calculated dietary $P$ and Ca concentrations: Normal P $9.2 \mathrm{mmol} \mathrm{P} / \mathrm{MJ}(5.6 \mathrm{~g} \mathrm{P} / \mathrm{kg}$ diet); Low P $4.6 \mathrm{mmol}$ $\mathrm{P} / \mathrm{MJ}$ (2.8 g P/kg diet); Normal Ca $9.5 \mathrm{mmol} \mathrm{Ca} / \mathrm{MJ}$ (7.5 g Ca/kg diet); Low Ca $4.8 \mathrm{mmol} \mathrm{Ca} / \mathrm{MJ}(3.8 \mathrm{~g} \mathrm{Ca} / \mathrm{kg}$ diet).

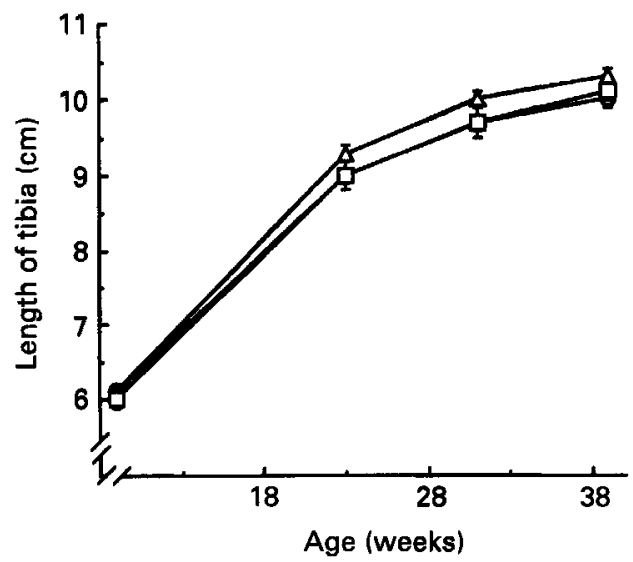

Fig. 7. Expt 2. Time course of growth of the tibia of female cats fed on diets containing either 4.6 or $9.2 \mathrm{mmol}$ phosphorus and 4.8 or $9.5 \mathrm{mmol}$ calcium/MJ. Values are means for seven or eight cats with their standard errors indicated by vertical bars. $(\triangle)$, Normal-phosphorus, normal-calcium diet; $(O)$, low-phosphorus, normal-calcium diet; ( $\square)$, low-phosphorus, low-calcium diet. Multivariate ANOVA, repeated measures $(P<0.05)$, revealed a significant effect of age on the length of the tibia. One-way ANOVA was performed to compared the three dietary groups at the same age: $P=0.21-0.84$. 


\section{Expt 2. Plasma minerals}

Plasma levels of $\mathrm{Ca}, \mathrm{Mg}$ and $\mathrm{P}$ were not affected by dietary composition (results not shown). In general, plasma mineral concentrations dropped with age.

\section{Expt 2. Plasma urea and creatinine}

Plasma levels of urea and creatinine rose significantly with age, but were not influenced by dietary treatment (results not shown).

\section{Expt 2. Bone development}

Tibia length was somewhat lower in the low-P groups relative to the normal-P, normal-Ca group, but the difference was not statistically significant (Fig. 7). There was no significant effect of diet on plasma activity of alkaline phosphatase (results not shown). Length, circumference, weight, volume, density and $\mathrm{Ca}, \mathrm{Mg}$ and $\mathrm{P}$ concentrations of femurs at 39 weeks of age were similar for all three dietary groups; average values were $9.4(\mathrm{SE} 0 \cdot 1) \mathrm{cm}$, 2.4 (SE 0.04) $\mathrm{cm}, 6.2$ (SE 0.2) $\mathrm{g}, 4.4\left(\right.$ SE 0.1) $\mathrm{cm}^{3}, 1.42$ (SE 0.01) g/ $\mathrm{cm}^{3}$, and 221 (SE 1), 3.5 $(\mathrm{SE} 0 \cdot 03$ ) and 103 (SE 1$) \mathrm{mg} / \mathrm{g}$ femur dry weight $(n 22)$ respectively.

\section{Expt 2. Mineral concentrations of organs}

Dietary groups did not differ with regard to concentrations of $\mathrm{Ca}, \mathbf{M g}$ or $\mathbf{P}$ in heart and liver (results not shown). Kidney concentrations of $\mathrm{Ca}$ were significantly depressed in cats fed on the low-P diets (Table 3). Kidney levels of $\mathbf{M g}$ and P were not affected by dietary composition.

\section{DISCUSSION}

The major objective of this study was to evaluate whether $\mathbf{P}$ restriction to half the recommended minimum level would sustain growth and mineralization of bone in female kittens. In Expt 1 the body weights of the cats fed on the low-P diet were significantly reduced at the age of 15 to 20 weeks. In Expt 2, body weights in the low-P, normal-Ca group also tended to be reduced during the first 10 weeks of the experiment. Apparently, a dietary level of $4.6 \mathrm{mmol} \mathrm{P} / \mathrm{MJ}(2.8 \mathrm{~g} \mathrm{P} / \mathrm{kg}$ diet $)$ does not allow body-weight gain similar to that sustained by $9.2 \mathrm{mmol} \mathrm{P} / \mathrm{MJ}(5.6 \mathrm{~g} \mathrm{P} / \mathrm{kg}$ diet $)$. Since maximum growth in rats is associated with reduced lifespan and higher incidences of tumours and kidney disease in later life (Ross et al. 1976; Pariza, 1987), maximum growth may not be a proper criterion by which to set nutrient requirements. Thus, it is uncertain whether the small reduction in body weight seen after $\mathbf{P}$ restriction should be considered as a disadvantageous effect.

In rats, $\mathbf{P}$ restriction to one quarter of the recommended level, which is based on attainment of maximum growth (National Research Council, 1978), significantly reduced $\mathrm{Ca}, \mathrm{Mg}$ and $\mathrm{P}$ contents of the femur (Schoenmakers et al. 1989). In the cats a reduction of dietary $\mathrm{P}$ level to half the minimum requirement produced a reduction of tibia length, this effect not being statistically significant. Restricted $P$ intake slightly raised the Ca content of the femur at the age of 39 weeks in Expt 1, but this was not seen in Expt 2. At the end of the experiments length, volume, density and $\mathrm{Mg}$ and $\mathrm{P}$ contents of femur were not significantly influenced by $P$ restriction nor by the Ca:P ratio. Thus, it appears that $P$ restriction had no major impact on bone development as assessed at the age of 39 weeks. In addition, $P$ restriction did not affect plasma alkaline phosphatase activity and urinary hydroxyproline excretion during the course of the experiment.

In both experiments the reduction of $\mathbf{P}$ intake prevented renal calcification as based on chemical and histological analysis. The anti-nephrocalcinogenic effect of $P$ restriction was independent of the $\mathrm{Ca}: \mathrm{P}$ ratio. In rats, $\mathrm{P}$-induced nephrocalcinosis is antagonized by urinary acidification (Kootstra et al. 1991). Thus, the observed renal calcification in the cats 
may have been enhanced by the relatively high urinary $\mathrm{pH}$ values. P-induced nephrocalcinosis may impair kidney function in rats (Schaafsma \& Visser, 1980; RitskesHoitinga et al. 1989). However, renal function in the cats fed on the normal-P diets was not impaired as based on plasma levels of urea and creatinine and creatinine clearance, which were within the normal range for cats. This can be explained by the fact that the degree of kidney calcification in the cats was less severe than that seen by others in rats given high$P$ diets. The nephrocalcinogenic effect of the normal- $v$. low-P diets in the young cats corroborates that of high $P$ intake observed by Lewis et al. (1978) in healthy adult cats, and by Ross et al. (1982) in cats with reduced renal mass. Renal disease is a major cause of death in the domestic cat (Cowgill, 1983), and Lucke \& Hunt (1967) observed a high incidence of nephrocalcinosis. Generally, the P content of commercial cat foods amply exceeds the recommended minimum level (Graser et al. 1981; Sauer et al. 1985). Thus, lowering of the $P$ level in cat diets may reduce the risk of renal disease.

$\mathrm{P}$ intake did not significantly affect retention of $\mathrm{Ca}$ and $\mathrm{Mg}$. At the age of 31-39 weeks, $\mathrm{Mg}$ retention was negative but plasma $\mathrm{Mg}$ concentration and alkaline phosphatase activity were unaffected. During the balance periods at the age of 31 and/or 39 weeks most cats lost weight. In Expt 2 there was a significant, positive correlation $(r 0.77, P<0.01, n 22)$ between body-weight gain and retention of $\mathrm{Mg}$. Thus, the observed whole-body $\mathrm{Mg}$ loss may be explained by a temporary reduction of body weight during the balance periods.

Restricted $\mathbf{P}$ intake resulted in depressed amounts of absorbed $\mathbf{P}$ and reduced urinary excretions of $\mathbf{P}$, which balanced each other so that $\mathbf{P}$ retention was unaffected during the period 15 to 39 weeks of age. Likewise, $\mathrm{Ca}$ and $\mathrm{Mg}$ retention values were not influenced by $\mathrm{P}$ restriction. Percentages of apparent absorption of $\mathrm{Ca}$ and $\mathrm{Mg}$ were highest in the cats fed on the low-P, low-Ca diet. Percentages of apparent absorption of $\mathbf{P}$ were lowered by reduced $P$ intake and raised by restricted $\mathrm{Ca}$ intake. The reduction of apparent $P$ absorption in the cats fed on the low-P diets is probably due to a greater portion of endogenous $\mathrm{P}$ in the faeces. The lowering effects of a higher dietary $\mathrm{P}$ level on $\mathrm{Ca}$ and $\mathrm{Mg}$ absorption values and that of a higher $\mathrm{Ca}$ intake on $\mathrm{Mg}$ absorption may be explained by the formation of an insoluble $\mathrm{Ca}-\mathrm{Mg}$-phosphate complex in the intestine (Brink et al. 1992).

Precipitation of struvite crystals in urine depends on the urinary concentrations of its components: when the activity product $\left[\mathrm{Mg}^{2+}\right] \times\left[\mathrm{NH}_{4}{ }^{+}\right] \times\left[\mathrm{PO}_{4}{ }^{3-}\right]$ exceeds the formation product, crystals will develop. A low urinary $\mathrm{pH}$ can prevent struvite urolithiasis because the activity product is diminished (Buffington et al. 1989). In Expt 1, urinary $\mathrm{pH}$ and $\mathrm{Mg}$ concentrations were slightly higher in the cats fed on the low-P diet, but urinary concentrations of $\mathbf{P}$ were markedly reduced. Urinary struvite saturation can be predicted using a nomogram (Buffington et al. 1989), and assuming that urinary concentrations of ammonium remained at a constant level it follows that urines of the cats fed on the low$P$ diet were less supersaturated than those of the cats fed on the normal-P diet. The difference between the two dietary groups was greatest until the age of 21 weeks. This is in agreement with our perception that precipitates were invariably present in urines from the cats fed on the normal-P diet, whereas in the cats fed on the low-P diet they were only found from the age of 21 weeks. The common presence of precipitates undoubtedly relates to the relatively high urinary $\mathrm{pH}$ values, which in turn were caused by the liberal use of carbonates to prepare the purified diets. The urinary $\mathrm{pH}$ values in cats generally range between 6.5 and 8.5 (Buffington et al. 1989).

In conclusion, dietary $P$ restriction to half the recommended minimum amount slightly reduced body-weight gain and tibia growth in female kittens. However, in order to sustain normal growth and bone mineralization while fed on the low-P diets the cats probably had to draw heavily on their compensatory mechanisms. This is indicated by reduced plasma 
levels of $P$ and the extremely low urinary $P$ concentrations from the age of 11 to 15 weeks. Therefore, a reduction of the dietary $P$ concentration to $4.6 \mathrm{mmol} \mathrm{P} / \mathrm{MJ}(2.8 \mathrm{~g} \mathrm{P} / \mathrm{kg}$ diet $)$ may be too drastic, at least until the age of 15 to 20 weeks. This certainly holds for diets based on natural ingredients which generally contain $\mathbf{P}$ sources that are not as readily available as those in our purified diets. On the other hand, $P$ restriction may have had a positive impact on the health of the cats. $\mathbf{P}$ restriction markedly lowered urinary $\mathbf{P}$ concentrations, which could lower the risk of struvite urolithiasis, and also prevented renal calcification, which may contribute to lowering the risk for renal disease. Thus, although $\mathrm{P}$ restriction to $4.6 \mathrm{mmol} \mathrm{P} / \mathrm{MJ}(2.8 \mathrm{~g} \mathrm{P} / \mathrm{kg}$ diet $)$ is discouraged, at least for weanling kittens, it seems reasonable to suggest that commercial cat foods with levels of available $P$ higher than $9.2 \mathrm{mmol} / \mathrm{MJ}(5.6 \mathrm{~g} \mathrm{P} / \mathrm{kg}$ diet) should be avoided.

F. J. H. Pastoor was supported by Rodi B.V., Opmeer, The Netherlands. We thank J. W. G. Vosmeer and C. J. W. M. Brandt for biotechnical assistance, H. Van Herck for clinical examination and $\mathrm{C}$. Van der Zwan for taking care of the cats.

\section{REFERENCES}

Brink, E. J., Beynen, A. C., Dekker, P. R., Van Beresteijn, E. C. H. \& Van der Meer, R. (1992). Interaction of calcium and phosphate decreases ileal magnesium solubility and apparent magnesium absorption in rats. Journal of Nutrition 122, 580-586.

Buffington, C. A., Cook, N. E., Rogers, Q. R. \& Morris, J. G. (1989). The role of diet in feline struvite urolithiasis syndrome. In Nutrition of the Dog and Cat, pp. 357-380 [I. H. Burger and J. P. W. Rivers, editors]. Cambridge: Cambridge University Press.

Carey, C. J. \& Morris, J. G. (1977). Biotin deficiency in the cat and the effect of hepatic propionyl CoA carboxylase. Journal of Nutrition 107, 330-334.

Cowgill, L. D. (1983). Diseases of the kidney. In Textbook of Veterinary Internal Medicine: Diseases of the Dog and Cat, pp. 1793-1879 [S. J. Ettinger, editor]. Philadelphia, PA: W. B. Saunders Company.

Finco, D. R. (1983). The role of phosphorus restriction in the management of chronic renal failure in the dog and cat. In Proceedings of the Kal Kan Symposium for Treatment of Small Animal Diseases, pp. 131-133 [E. Van Marthens, editor]. Vernon, CA: Kal Kan Foods, Inc.

Graser, D. H., Hamar, D. W. \& Lewis, L. D. (1981). The consistency of dietary minerals in commercial cat food and their relationship to feline urolithiasis. Feline Practice 11(2), $41-47$.

Kootstra, Y., Ritskes-Hoitinga, J., Lemmens, A. G. \& Beynen, A. C. (1991). Diet-induced calciuria and nephrocalcinosis in female rats. International Journal for Vitamin and Nutrition Research 61, 100-101.

Lawler, D. F., Sjolin, D. W. \& Collins, J. E. (1985). Incidence rates of feline lower urinary tract disease in the United States. Feline Practice 15(5), 13-16.

Lewis, L. D., Chow, F. H. C., Taton, G. F. \& Hamar, D. W. (1978). Effects of various dietary mineral concentrations on occurrence of feline urolithiasis. Journal of the American Veterinary Medical Association 172, $559-563$.

Lewis, L. D., Morris, M. L. \& Hand, M. S. (1987). Small Animal Clinical Nutrition III, pp. 8-1-8-51. Topeka, Kansas: Mark Morris Associates.

Lucke, V. M. \& Hunt, A. C. (1967). Renal calcification in the domestic cat. Pathologia Veterinaria 4, $120-136$.

Mallory, F. B. (1961). Pathological Technique, p. 144. New York, NY: Hafner Publishing.

National Research Council (1978). Nutrient Requirements of Laboratory Animals. Washington DC: National Academy of Sciences.

National Research Council (1986). Nutrient Requirements of Cats. Washington DC: National Academy Press.

Pariza, M. W. (1987). Dietary fat, calorie restriction, ad libitum feeding, and cancer risk. Nutrition Reviews $\mathbf{4 5}$, $1-7$.

Pastoor, F. J. H. (1993). Interactions of dietary minerals in the cat. PhD Thesis, Utrecht University, The Netherlands.

Pastoor, F. J. H., Van Herck, H., Van 't Klooster, A. Th. \& Beynen, A. C. (1991 $a$ ). Biotin deficiency in cats as induced by feeding a purified diet containing egg white. Journal of Nutrition 121, S73-S74.

Pastoor, F. J. H., Van 't Klooster, A. Th. \& Beynen, A. C. (1990). An alternative method for the quantitative collection of faeces and urine of cats as validated by the determination of mineral balance. Zeitschrift für Versuchstierkunde 33, 259-263.

Pastoor, F. J. H., Van 't Klooster, A. Th., Lankhorst, A., Mathot, J. N. J. J. \& Beynen, A. C. (1991 b). An alternative method for the collection of urine and feces and its application in measuring urinary mineral excretion in cats fed diets containing various amounts of phosphorus. Journal of Nutrition 121, S85-S86. 
Pastoor, F. J. H., Van 't Klooster, A. Th., Mathot, J. N. J. J. \& Beynen, A. C. (1994a). Increasing calcium intakes lower urinary concentrations of phosphorus and magnesium in adult ovariectomized cats. Journal of Nutrition 124, 299-304.

Pastoor, F. J. H., Opitz, R., Van 't Klooster, A. Th. \& Beynen, A. C. (1994b). Dietary calcium chloride vs. calcium carbonate reduces urinary $\mathrm{pH}$ and phosphorus concentration, improves bone mineralization and depresses kidney calcium level in cats. Journal of Nutrition 124, 2212-2222.

Ritskes-Hoitinga, J., Lemmens, A. G., Danse, L. H. J. C. \& Beynen, A. C. (1989). Phosphorus-induced nephrocalcinosis and kidney function in female rats. Journal of Nutrition 119, 1423-1431.

Ross, L. A., Finco, D. R. \& Crowell, W. A. (1982). Effect of dietary phosphorus restriction on the kidneys of cats with reduced renal mass. American Journal of Veterinary Research 43, 1023-1026.

Ross, M. H., Lustbader, E. \& Bras, G. (1976). Dietary practices and growth responses as predictors of longevity. Nature 262, 548-553.

Sauer, L. S., Hamar, D. \& Lewis, L. D. (1985). Effect of dietary mineral composition on urinary mineral concentration and excretion by the cat. Feline Practice 15(4), 10-15.

Schaafsma, G. \& Visser, R. (1980). Nutritional interrelationships between calcium, phosphorus and lactose in rats. Journal of Nutrition 110, 1101-1111.

Schoenmakers, A. C. M., Ritskes-Hoitinga, J., Lemmens, A. G. \& Beynen, A. C. (1989). The influence of dietary phosphorus restriction on calcium and phosphorus metabolism in rats. International Journal for Vitamin and Nutrition Research 59, 200-206.

Scott, P. P. (1965). Minerals and vitamins in feline nutrition. In Canine and Feline Nutrition Requirements, pp. 75-89 [O. Graham-Jones, editor]. London: Pergamon Press.

SPSS Inc. (1988a). SPSS/PC+ Advanced Statistics V2.0. Chicago, IL: SPSS Inc.

SPSS Inc. (1988b). SPSS/PC+TM V2.0. Base Manual. Chicago, IL: SPSS Inc.

Steel, R. G. D. \& Torrie, J. H. (1981). Principles and Procedures of Statistics. A Biochemical Approach, 2nd ed. Tokyo: McGraw-Hill International Book Co. 